tục với cõ mẫu lớn hơn nữa.

\section{KẾT LUẬN}

Đa hình đơn gen MTHFR C677T làm tăng nguy cơ STLT KRNN. Nhóm STLT KRNN mang gen MTHFR có xu hướng bệnh lý có số lần sấy thai trong tiền sử trung bình là 2,97 lần, cao hơn nhóm không mang gen 2,28 lần $(p=0,05)$, thời điểm thai sẩy trung bình trong tiền sử của nhóm mang gen là 8,47 tuần.

MTHFR C677T làm tăng nguy cơ xuất hiện triệu chứng doạ sẩy thai trong 3 tháng đâuu (tăng nguy cơ đau bụng 5,6 lần $(p=0,038)$, tăng nguy cơ ra máu âm đạo 3,6 lần $(p=0,043))$.

\section{TÀI LIỆU THAM KHẢO}

1. Practice Committee of the American Society for Reproductive Medicine. Evaluation and treatment of recurrent pregnancy loss: a committee opinion. Fertility and Sterility. 2012; vol. 98, (5), pp. 1103-1111.

\section{Balasubramaniam,}

Amarasekara.

Analysis

Kotalawala,

Methylenetetrahydrofolate Reductase (MTHFR) Polymorphisms (C677t \& A1298c) in Recurrent Pregnancy Loss (RPL). Nessa Journal of Gynecology.2017; vol. 1, no. 4, pp. 1-26, 2017.
3. Đỗ Tiến Dũng. Huyết khối và sảy thai liên tiếp. Tạp chí Y học lâmm sàng Bệnh viện Bạch Mai. 2010; vol. 50, pp. 12-16.

4. Barut MU, Bozkurt M, Kahraman M. Thrombophilia and Recurrent Pregnancy Loss: The Enigma Continues. Medical Science Monitor 2018; vol. 24, pp. 4288-4294.

5. SC Liew; ED Gupta, "Methylenetetrahydrofolate reductase (MTHFR) C677T polymorphism: Epidemiology, metabolism and the associated diseases," European Journal of Medical Genetics. 2015; vol. 58, pp. 1-10.

6. Vandana Rai. Methylenetetrahydrofolate Reductase C677T Polymorphism and Recurrent Pregnancy Loss Risk in Asian Population: A Metaanalysis. Indian Journal of Clinical Biochemistry. 2016; vol. 31, no. 4, pp. 402-413.

7. Tranquilli AL, Saccucci F, Giannubilo SR. Unexplained fetal loss: the fetal side of thrombophilia. Fertility and Sterility 2010; vol. 94, no. 378-380.

8. Liew S, Gupta E. Methylenetetrahydrofolate reductase (MTHFR) C677T polymorphism: Epidemiology, metabolism and the associated diseases. European Journal of Medical Genetics. 2015; vol. 58, pp. 1-10, 2015.

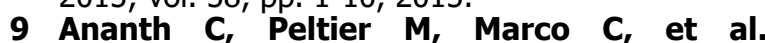
Associations between 2 polymorphisms in the methylenetetrahydrofolate reductase gene and placental abruption. American Journal of Obstetrics and Gynecology. 2007; vol. 197, no. 4, p. 385.

\title{
ĐA HÌNH ĐƠ'N NUCLEOTIDE RS2856718 CỦA GEN HLA-DQ TRÊN BỆNH NHÂN UNG THƯ BIỂU MÔ TẾ BÀO GAN
}

\author{
Mạc Thị Tịnh ${ }^{1,2}$, Nguyễn Trọng Tuệ ${ }^{1}, H_{\hat{̀}} C^{2}$ ẩm Tú ${ }^{1}$,
} Nguyễn Hoàng Việt ${ }^{1}$, Nguyễn Thu Thúy $^{1}$

\section{TÓM TẮT}

Ung thư gan nguyên phát là bệnh ung thư phổ biến và có tỉ lệ tử vong cao. Gen HLA-DQ mã hóa các chuối polypeptid của phân tử MHC Iớp II tham gia hoạt hóa tế bào trình diện kháng nguyên trong đáp ứng miễn dịch. Đa hình đơn nucleotide (SNP) rs2856718 của gen HLA-DQ có thể liên quan tới nhiễm virus viêm gan $B$ mãn tính và nguy cơ ung thư biểu mô tế bào gan. Nghiên cứu này được thực hiện nhằm mục tiêu xác định sự phân bố của SNP rs2856718, đồng thời đánh giá mối liên quan giữa SNP này với nguy cơ mắc ung thư biểu mô tế bào gan. Kỹ thuật RT-PCR được sứ dụng để xác định kiểu gen SNP rs2856718 trên 93 bệnh nhân ung thư biểu mô tế bào

${ }^{1}$ Trung tâm Nghiên cứu Gene - Protein, Trường Đại học Y Hà Nội

2̇rường Đại họ Y Hải Phòng

Chịu trách nhiệm chính: Nguyễn Thu Thúy

Email: nguyenthuthuy@hmu.edu.vn

Ngày nhận bài: 9.8.2021

Ngày phản biên khoa học: 8.10 .2021

Ngày duyệt bài: 15.10 .2021 gan và 93 người khỏe mạnh. Kết quả đã xác định được tỷ lệ kiểu gen $G G, A G, A A$ ở nhóm bệnh là $39,8 \%, 46,2 \%, 14 \%$ và nhóm chứng là $30,1 \%$, $53,8 \%, 16,1 \%$. Chưa tìm thấy mối liên quan giữa SNP rs2856718 với nguy cơ ung thư biểu mô tế bào gan cũng như với một số yếu tố nguy cơ khác.

Tư khóa: SNP, rs2856718, HLA-DQ, ung thư biểu mô tế bào gan.

\section{SUMMARY \\ SINGLE NUCLEOTIDE POLYMORPHISM RS2856718 IN HLA-DQ GENE ON HEPATOCELLULAR CARCINOMA PATIENTS}

Primary liver cancer is a common cancer with a high mortality rate. The HLA-DQ gene encodes polypeptide chains of MHC class II molecules involved in the activation of antigen-presenting cells in the immune response. The single nucleotide polymorphism (SNP) rs2856718 of HLA-DQ gene may be associated with chronic hepatitis $B$ virus infection and hepatocellular carcinoma (HCC). This study was aimed to determine the distribution of SNP rs2856718, and to evaluate the association between this SNP and the risk of HCC. RT-PCR technique was used to 
genotype SNP rs2856718 in 93 HCC patients and 93 healthy individuals. The results determined that the rate of GG, AG, and AA genotypes was $39.8 \%, 46.2 \%$, $14 \%$ for the HCC group and $30.1 \%, 53.8 \%, 16.1 \%$ for the control group, respectively. No association was found between SNP rs2856718 with the risk of HCC and other risk factors.

Keywords: SNP, rs2856718, HLA-DQ, hepatocellular carcinoma.

\section{I. ĐĂT VẤN ĐỀ}

Theo GLOBOCAN năm 2020, ung thư gan trên thế giới có tỉ lệ mắc mới đứng thứ $6(905.677 \mathrm{ca}$, $4.7 \%)$ và tỉ lệ tử vong đứng thứ $2(830.180 \mathrm{ca}$, $8.3 \%$ ) trong các loại ung thư [1]. Riêng tại Viêt Nam ung thư gan đứng thứ nhất về cả tỉ lệ mắc mới $(26.418 \mathrm{ca}, 14.5 \%)$ và tỉ lệ tử vong $(25.272$ $\mathrm{ca}, 20.6 \%)[1]$. Ung thư biểu mô tế bào gan (HCC) là một dạng chủ yếu của ung thư gan nguyên phát. Nếu được phát hiện sớm, bệnh nhân $\mathrm{HCC}$ có khả năng được chữa khỏi bằng phẫu thuật hoặc cấy ghép. Vì vậy, việc chẩn đoán sớm là rất quan trong giúp tăng hiêu quả điêu trị, giảm tỉ lệ tử vong. Vì HCC là một bệnh phức tapp do nhiều yếu tố nguy cơ như nhiễm virus viêm gan $B$ và $C$, $x o ̛$ gan, nghiện rượu, tiền sử gan nhiểm mõ̃... nên cần sự kết hợp các dấu ấn sinh học để việc chẩn đoán chính xác hơn. Do đó việc phát hiện các gen nhạy cảm với HCC là rất cần thiết mặc dù đã có một số dấu ấn được phát hiên trước đó.

Kháng nguyên bạch cầu người (Human Leucocyte Antigen - HLA) là một hệ thống gen mã hóa phức hợp tương thích mô chính, một protein bề mặt ở người chịu trách nhiệm điều hòa hệ miễn dịch. Phức hợp HLA gồm hơn 200 gen nằm gần nhau trên nhiễm sắc thể số 6 (6p21) và dài xấp xỉ $3600 k b$ [2]. HLA-DQ là môt protein thụ thể bề mặt tế bào tìm thây ở các tế bào trình diện kháng nguyên. Các HLA-DQ có tính đa hình cao đăc biêt là trong exon 2, mã hóa cho các vị trí gắn kháng nguyên và đóng vai trò quan trọng trong việc đưa kháng nguyên virus vào các tế bào miễn dịch từ đó giúp thanh thải các tế bào bị nhiễm virus hay tế bào $u$ [3]. Đa hình rs2856718 nằm trong khu vực giữa các gen HLA-DQA2 và HLA-DQB1, có thể ảnh hưởng thông qua việc tăng mức độ biểu hiện của gen HLA-DQ và tăng cường hoạt tính HLA-DQ [4]. Đã có nhiều nghiên cứu đánh giá mối liên quan giữa SNP rs2856718 của gen HLA-DQ và tính nhạy cảm với $\mathrm{HCC}$ liên quan đến $\mathrm{HBV}$, tuy nhiên kết quả còn nhiều tranh cãi $[3,4]$. Vì vậy nghiên cứu này được tiến hành với mục tiêu: 1-Xác định tỉ lệ kiểu gen, tần số alen SNP rs2856718 của gen HLA-DQ trên nhóm bệnh nhân HCC và nhóm chứng; 2-Phân tích mối liên quan giữa SNP rs2856718 với HCC và một số yếu tố nguy cơ của HCC.

\section{II. ĐỐI TƯỚNG VÀ PHƯƠNG PHÁP NGHIÊN CỨU}

\section{1. Đối tượng nghiên cứu}

Nhóm bềnh: Tiêu chuẩn lựa chọn: bệnh nhân được chẩn đoán xác định $\mathrm{HCC}$ bằng giải phẫu bênh hoc tai Bênh viên K3 cơ sở Tân Triều Hà Nội, có đầy đủ thông tin hồ sơ bệnh án cần thu thập và đồng ý tham gia. Tiêu chuẩn loại trừ: không kèm theo các ung thư khác hay các bệnh lý về gan khác.

Nhóm chứng: Những người đến khám sức khỏe tại Bệnh viện Đại Học Y Hà Nội, không mắc HCC hay bất cứ loại ung thư nào khác và không có các bệnh lý về gan, tương ứng về tuổi và giới với nhóm bênh.

\section{Phương pháp nghiên cứu}

Thiết kế nghiên cứu: Nghiên cứu mô tả cắt ngang có nhóm đối chứng. Mẫu được chọn ngẫu nhiên đơn, cõ̃ mẫu tính dựa trên cồng thức tính cõ mẫu ước lượng một tỷ lệ:

$$
n=Z_{(1-\alpha / 2)}^{2} \frac{p(1-p)}{\Delta^{2}}
$$

Trong đó: $p=0,32$ (tỷ lệ ước tính từ nghiên cứu của Gao 2016), $\Delta=\mathbf{0}, 1$ (khoảng sai lệch mong muốn), $a=0,05$ (mức ý nghĩa thống kê), $Z_{(1-a / 2)}=1,96$ (hể số tin cậy). Tính được $n=84$. Như vậy, cõ̃ mẫu tối thiểu mỗi nhóm là 84 .

- Nghiên cứu được thực hiện trên 93 mẫu bệnh và 93 mẫu chứng.

Thời gian nghiên cứu: 7/2020 - 10/2021

Địa điểm nghiên cứu: Trung tâm GenProtein Trường Đại học $Y$ Hà nội, Bệnh viện K3 cơ sở Tân Triều Hà Nội, Bệnh viện Trường Đại học Y Hà Nôi.

Biến số và chỉ số nghiên cứu: chỉ số lâm sàng gồm tuổi, giới, nhiễm HBV, nhiễm HCV, sử dụng rượu; chỉ số cận lâm sàng gồm độ mố học ung thư' (độ 1, độ 2, độ 3, độ 4) xơ gan, chỉ số AFP, kiểu gen rs2856718.

Phương pháp thu thập số liệu: hồi cứu dữ liệu có sẵn trong bệnh án.

Quy trình kỹ thuật: lấy máu tĩnh mạch, tách DNA từ máu sử dụng kit của Promega (USA), Real-time PCR sử dụng hóa chất của Applied Biosystems (USA).

Quy trinh real-time PCR:- Thành phân phản ứng Realtime-PCR: $2.75 \mu \mathrm{l} \mathrm{H2O}, 5 \mu \mathrm{l}$ Taqman $^{\mathrm{TM}}$ Fast Advanced Master Mix 2X, 0.25 $\mu \mathrm{l}$ (primer + probe rs2856718 40X), 2ul DNA khuôn (50ng/ $\mu \mathrm{l})$. Probe rs2856718 có trình tự như sau: $5^{\prime}$ CCTCTGGCAGGTTAAGAAGAGCTGT[C/T]TAATCC CATGGCCTGTCCTCCCACA-3'. 
- Chu trình nhiệt: $60^{\circ} \mathrm{C} / 30$ giây, $95^{\circ} \mathrm{C} / 10$ phút, 40 chu kỳ (biến tính ở $95^{\circ} \mathrm{C} / 15$ giây, kéo dài ở $60^{\circ} \mathrm{C} / 1$ phút), $60^{\circ} \mathrm{C} / 30$ giây.

Xử lý và phân tích số liệu: Kiểm định Fisher test trong phân tích sự khác nhau của biến trên 2 mẫu độc lập (với cỡ mẫu nhỏ) trên phần mềm thống kê SPSS 20.0. Phân tích mối liên quan giữa các biến số thông qua tỷ suất chênh (OR) với khoảng tin cậy 95\% (95\%CI). Sự khác biệt có ý nghĩa thống kề khi $p<0,05$.

Đạo đức nghiên cứu: Đề tài đã được hội đồng đạo đức của trường Đại học Y Hà Nội chấp thuận theo quyết định số 109/HĐĐĐĐHYHN ngày $17 / 08 / 2020$. Mọi thông tin cá nhân của đối tượng nghiên cứu được bảo mật. Số liệu thu thập được tiến hành một cách trung thực, chỉ được phục vụ cho mục đích nghiên cứu.

\section{KẾT QUẢ NGHIÊN CỨU}

1. Đặc điểm chung của nhóm nghiên cứu. Đặc điểm chung của nhóm nghiên cứu được thể hiện ở bảng 1 . Tuổi trung bình của nhóm bệnh nhân HCC là 55,67 $\pm 8,97$, tương tự nhóm chứng là $55,80 \pm 9,04$. Độ tuổi $\leq 60$ chiếm tỉ lệ cao hớn độ tuổi > 60, với tỉ lệ lần lượt là $72 \%$ và $28 \%$ ở nhóm HCC và $69,9 \%$ và $31,1 \%$ ở nhóm chứng. Tỉ lệ nam và nữ là $94,6 \%$ và $5,4 \%$ ở nhóm HCC, $90.3 \%$ và $9.7 \%$ ở nhóm chứng. Sự khác biệt về tỉ lệ độ tuổi $(\leq 60,>60)$ và giới tính giữa hai nhóm mẫu không có ý nghĩa thống kê ( $p>0,05)$. Trong 93 mẫu HCC, tî lệ nhiễm HBV là $81,7 \%$, không nhiếm HBV là $18,3 \%$ và tỉ lệ nhiễm HCV là 8,6\%, không nhiễm HCV là 91,4\%. Tỉ lệ bệnh nhân HCC bị xơ gan là $28 \%$ và không xơ gan là $72 \%$. Nhóm HCC có chỉ số nồng độ AFP $>20 \mathrm{ng} / \mathrm{ml}$ là $53,4 \%$ và $A F P \leq 20$ là $46,6 \%$. Độ mô học $\mathrm{HCC}$ chủ yếu là độ 2 và độ 3 , trong đó HCC độ 2 chiếm tỉ lệ cao nhất là $65,1 \%$, HCC độ 4 có tỉ lệ thấp nhất là $1,6 \%$.

Bảng 1. Đặc điểm chung của nhóm nghiên cứu

\begin{tabular}{|l|l|l|l|} 
Đặc điểm & Nhóm & Nhóm & $\mathbf{p}$
\end{tabular}

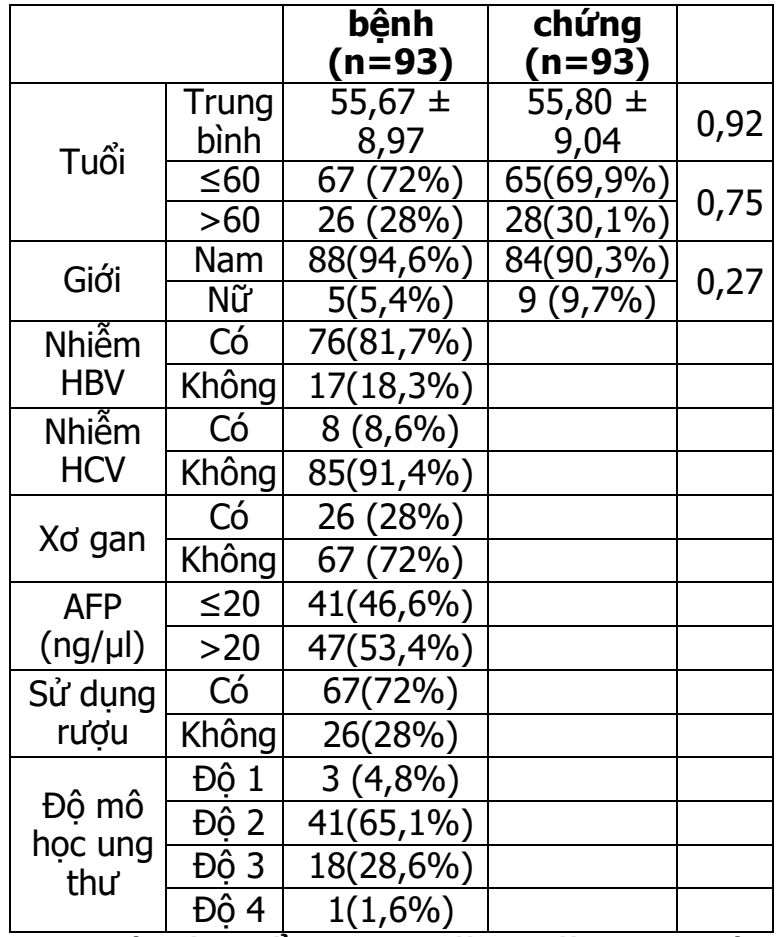

2. Tỉ lệ kiếu gen, tân số alen của rs2856718 và mối liên quan với nguy cơ ung thư biểu mô tế bào gan. Kết quả phân tích ở bảng 2 cho thấy, tỉ lệ kiểu gen $G G, A G, A A$ ở nhóm bệnh là $39,8 \%, 46,2 \%, 14,0 \%$ và ở nhóm chứng là $30,1 \%, 53,8 \%, 16,1 \%$. Kiểu gen $A G$ có tỉ lệ cao nhất và kiếu gen $A A$ là thấp nhất ở cả nhóm bệnh và nhóm chứng. Tỉ lệ alen $A$ và G ở nhóm bệnh là $37,1 \%$ và $62,9 \%$, ở nhóm chứng là $43 \%$ và $57 \%$. Tỷ lệ alen $\mathrm{G}$ cao hơn alen $\mathrm{A}$ ở cả 2 nhóm. Sự khác biệt về tỉ lệ kiểu gen và tần số alen của SNP rs2856718 ở nhóm bệnh và nhóm chứng không có ý nghĩa thống kê $(p=0,24$ và $p=0,38)$. Khi so sánh theo các mô hình đồng hợp (GG và $A A)$, dị hợp ( $A A$ và $A G)$, di truyền lặn ( $G G$ và $A A+A G)$ và di truyền trội ( $A A$ và $G G+A G)$ cũng đều cho thấy sự khác biệt là không có ý nghĩa thống kê với p>0,05.

Bảng 2. Tỉ lệ kiểu gen, tân số alen của rs2856718 và môi liên quan với nguy cớ ung thư biểu mô tế bào gan

\begin{tabular}{|c|c|c|c|c|c|c|c|c|}
\hline \multirow{2}{*}{\multicolumn{2}{|c|}{ Kiểu gen, alen }} & \multicolumn{2}{|c|}{$\begin{array}{c}\text { Nhóm chứng } \\
(n=93)\end{array}$} & \multicolumn{2}{|c|}{$\begin{array}{c}\text { Nhóm bệnh } \\
(n=93)\end{array}$} & \multirow[t]{3}{*}{ OR } & \multirow[t]{2}{*}{ (95\%CI) } & \multirow[t]{2}{*}{ p } \\
\hline & & $n$ & $\%$ & $n$ & $\%$ & & & \\
\hline \multirow{2}{*}{ Kiểu alen } & $A$ & 80 & 43 & 69 & 37,1 & & & \multirow{2}{*}{0,24} \\
\hline & G & 106 & 57 & 117 & 62,9 & 1,28 & $0,85-1,94$ & \\
\hline \multirow{3}{*}{ Kiểu gen } & GG & 28 & 30,1 & 37 & 39,8 & & & \multirow{3}{*}{0,38} \\
\hline & AG & 50 & 53,8 & 43 & 46,2 & & & \\
\hline & AA & 15 & 16,1 & 13 & 14,0 & & & \\
\hline \multirow{2}{*}{$A A$ và $A G$} & $\mathrm{AA}$ & 15 & 23,1 & 13 & 23,2 & 1 & & \multirow{2}{*}{0,99} \\
\hline & AG & 50 & 76,9 & 43 & 76,8 & 0,99 & $0,43-2,32$ & \\
\hline
\end{tabular}


VIETNAM MEDICAL JOURNAL N² - NOVEMBER - 2021

\begin{tabular}{|c|c|c|c|c|c|c|c|c|}
\hline \multirow{2}{*}{$A A$ và $G G$} & AA & 15 & 34,9 & 13 & 26 & 1 & & \multirow{2}{*}{0,35} \\
\hline & GG & 28 & 65,1 & 37 & 74 & 1,5 & $1,63-3,71$ & \\
\hline \multirow{2}{*}{$A A+A G$ và $G G$} & $A A+A G$ & 65 & 69,9 & 56 & 60,2 & 1 & & \multirow{2}{*}{0,17} \\
\hline & GG & 28 & 30,1 & 37 & 39,8 & 1,5 & $0,84-2,82$ & \\
\hline \multirow{2}{*}{$\begin{array}{c}\text { AA và } \\
\text { GG+AG }\end{array}$} & AA & 15 & 16,1 & 13 & 14 & 1 & & \multirow{2}{*}{0,68} \\
\hline & $\mathrm{GG}+\mathrm{AG}$ & 78 & 83,9 & 80 & 86 & 1,18 & $0,53-2,65$ & \\
\hline
\end{tabular}

Nghiên cứu cũng đánh giá mối liên quan giữa rs2856718 với một số đặc điểm và yếu tố nguy cơ của ung thư biểu mô tế bào gan (bảng 3). So sánh tỉ lệ các kiểu gen các kiểu gen $G G, A G$ và $A A$ của SNP giữa nhóm mẫu $\mathrm{HCC}$ nhiễm HBV và nhóm mẫu HCC không nhiễm HBV, không thây có sự khác biệt có ý nghĩa thống kê $(p=0,51)$. Tương tự, tỉ lề các kiểu gen của SNP giữa nhóm mẫu $\mathrm{HCC}$ nhiểm $\mathrm{HCV}$ và $\mathrm{HCC}$ không nhiễm $\mathrm{HCV}$ cũng không khác biệt có ý nghĩa thông kê

$(p=0,69)$. Sự phân bố các kiểu gen của SNP rs2856718 ở nhóm bệnh nhân có xơ gan không khác biệt có ý nghĩa thông kê với nhóm bệnh nhân không xơ gan $(p=0,17)$. Khi so sánh giữa nhóm HCC có sử dụng rượu với không sử dụng rượu, giữa nhóm HCC có AFP tăng với nhóm HCC có AFP bình thường và giữa các nhóm có độ mô học HCC khác nhau cũng đều cho thấy sự khác biệt về tỉ lệ kiểu gen là không có ý nghĩa thống kề với $\mathrm{p}>0,05$.

Bảng 3. Môi liên quan giữa rs2856718 với một số đặc điểm và yếu tố nguy cơ HCC

\begin{tabular}{|c|c|c|c|c|c|c|c|c|}
\hline \multirow{3}{*}{\multicolumn{2}{|c|}{ Đặc điểm và yếu tố nguy cơ }} & \multirow{2}{*}{\multicolumn{2}{|c|}{ GG }} & \multirow{2}{*}{\multicolumn{2}{|c|}{ AG }} & \multirow{2}{*}{\multicolumn{2}{|c|}{ AA }} & \multirow{3}{*}{$\mathbf{p}$} \\
\hline & & & & & & & & \\
\hline & & $\mathbf{n}$ & $\%$ & $\mathbf{n}$ & $\%$ & $\mathbf{n}$ & $\%$ & \\
\hline \multirow{2}{*}{ Nhiễm HBV } & Có & 32 & 42,1 & 33 & 43,4 & 11 & 14,5 & \multirow{2}{*}{0,51} \\
\hline & Không & 5 & 29,4 & 10 & 58,8 & 2 & 11,8 & \\
\hline \multirow{2}{*}{ Nhiễm HCV } & Có & 4 & 50,0 & 4 & 50,0 & 0 & 0 & \multirow{2}{*}{0,69} \\
\hline & Không & 33 & 38,8 & 39 & 45,9 & 13 & 15,3 & \\
\hline \multirow[b]{2}{*}{ Xơ gan } & Có & 13 & 50,0 & 8 & 30,8 & 5 & 19,2 & \multirow[b]{2}{*}{0,17} \\
\hline & Không & 24 & 35,8 & 35 & 52,2 & 8 & 11,9 & \\
\hline \multirow{2}{*}{ Sử dụng rượu } & Có & 28 & 41,8 & 33 & 49,3 & 6 & 9,0 & \multirow[b]{2}{*}{0,08} \\
\hline & Không & 9 & 34,6 & 10 & 38,5 & 7 & 26,9 & \\
\hline \multirow{2}{*}{ AFP (ng/ml) } & $\leq 20$ & 16 & 39,0 & 20 & 48,8 & 5 & 12,2 & \multirow{2}{*}{0,98} \\
\hline & $>20$ & 19 & 40,4 & 22 & 46,8 & 6 & 12,8 & \\
\hline \multirow{4}{*}{$\begin{array}{l}\text { Độ mô học } \\
\text { ung thư }\end{array}$} & Độ 1 & 1 & 0,3 & 2 & 0.7 & 0 & 0 & \multirow{4}{*}{0,59} \\
\hline & Độ 2 & 17 & 41,5 & 18 & 43,9 & 6 & 14,6 & \\
\hline & Độ 3 & 4 & 22,2 & 9 & 0,5 & 5 & 27,8 & \\
\hline & Độ 4 & 0 & 0 & 1 & 100 & 0 & 0 & \\
\hline
\end{tabular}

\section{BÀN LUÂN}

Tuổi của đối tượng nghiên cứu là yếu tố phản ánh quá trình tích lũy, tiếp xúc với các tác nhân ung thư. Trong nghiên cứu, nhóm bệnh nhân ung thư biểu mô tế bào gan có độ tuổi phổ biến là từ 60 tuổi trở xuống (72\%). Tuổi trung bình của nhóm bệnh là 55,67, tương đồng với tuổi trung bình của nhóm HCC trong nghiên cứu của Gao và cộng sự (2016) là 55,96 và cao hơn so với nghiên cứu của Al-Qahtani và cộng sự (2014) với tuổi trung bình là 51 , Ji và cộng sự (2014) là 53 , Hu và cộng sự (2012) là $52,9[5,3,6,7]$. Tuy nhiên sự khác nhau về tuổi trung bình không quá lớn, có thể do sự sai khác về cỡ mẫu. Tỷ lệ nam trong nhóm HCC chiếm 94,6\%, trong khi nữ chỉ có $5,4 \%$. Tất cả các nghiên cứu về ung thư biểu mô tế bào gan đều cho thây tỷ lệ bệnh nhân nam luôn cao hơn nữ, thậm chí gấp nhiều lần $[3,5,6,7]$. Nguyên nhân có thể do nam giới phơi nhiễm với các yếu tố nguy cơ của HCC như rượu, bia, thuốc lá, viêm gan $B$, béo phì, tiểu đường nhiêu hơn nữ giới.

Trong cả hai nhóm, tỷ lệ alen $A(0,371)$ thấp hơn alen $G(0,629)$, phù hợp với dữ liệu tham chiếu ở người Việt Nam với tần số alen $\mathrm{A}$ của r2856718 là 0,435 [8]. Tuy nhiên, không có sự khác biêt về sư phân bố tỷ lê alen giữa hai nhóm. Tỷ lệ kiểu gen $A G$ nhiều nhất và tỷ lệ kiểu gen GG lớn hơn AA. Trong khi nghiên cứu của Gao và cộng sự (2016), Hu và cộng sự (2012) lại có tỷ lê kiểu gen AA lớn hơn GG ở cả nhóm bênh và nhóm chứng, nghiên cứu của Al-Qahtani và cộng sự (2014) cũng có tỷ lệ kiểu gen AA lớn hơn GG ở nhóm bệnh, nhưng ở nhóm chứng lại có tỷ lệ GG lớn hởn AA $[5,7,3]$. Như vây, tỷ lê kiểu gen ở nhóm chứng của chúng tôi giống với nghiên cứu của nhóm Al-Qahtani (2014) trên quần thể người Ả Rập Xê UUt [3]. Do các quần 
thể khác nhau có nguồn gốc khác nhau nên có sự khác nhau về cấu trúc haplotype và tần số alen. Với cõ̃ mẫu 93 bệnh nhân HCC, nghiên cứu chưa tìm thấy mối liên quan giữa tỷ lệ kiểu gen, tần số alen với ung thư biểu mô tể bào gan. Trong khi, nghiên cứu của Gao và cộng sự (2016) trên bệnh nhân HCC người Trung Quốc cho thây, kiểu gen HLA-DQ rs2856718 AG, GG và alen $\mathrm{G}$ chiếm tỷ lệ lớn ở nhóm HCC so với nhóm chứng, có thể làm tăng nguy cơ HCC liên quan đến HBV ở người khỏe mạnh [5]. Ngược lại, nghiên cứu của Xu và cộng sự (2018) cũng trền quần thể người Trung Quốc cho rằng, alen $\mathrm{G}$ của rs 2856718 làm giảm nguy cơ tiến triển HCC từ viêm gan $B$ mãn tính [4]. Nghiên cứu của chúng tôi bị hạn chế về cõ mầu nhỏ, dẫn tới tính đại diên chưa cao nên khi phân tích có thể chưa đủ để nhìn thấy các mối tương quan.

Không có mối liên quan nào được tìm thây giữa tỷ lệ kiểu gen của rs2856718 với các yếu tố nguy cơ như nhiếm HBV, HCV, xơ gan, tình trạng sứ dụng rượu, tăng AFP hay với đặc điểm ung thư mô học ở nhóm bệnh trong nghiên cứu của chúng tôi. Nghiên cứu đầu tiên về rs2856718 của Mbarek và cộng sự (2011) tại Nhật Bản cho thây, SNP này có tương quan mạnh với nhiếm viêm gan $\mathrm{B}$ mạn tính. Tuy nhiên, theo nghiên cứu phân tích tổng hợp bởi Xu và cộng sự (2018) trên 9 nghiên cứu, HLA-DQ rs2856718 có tương quan với sự giảm nguy cơ nhiếm HBV và khả năng tự thải trừ $\mathrm{HBV}$, nhưng không có tương quan với tiến triển xơ gan từ viêm gan $\mathrm{B}$ mãn tính [4]. Nghiên cứu của Al-Qahtani và cộng sự (2014) tại Â Rập Xê Út cho thây, rs2856718 có tương quan nghịch với nguy cơ nhiễm $\mathrm{HBV}$, và tương quan mạnh với tự thải trừ HBV. Tần suất của alen G của rs2856718 ở các cá thể đã thải trừ $\mathrm{HBV}$ cao hơn ở bệnh nhân hiện mắc viêm gan $B$, cho thấy alen $G$ có thể đóng vai trò quan trọng trong việc thải trừ virus viêm gan $B$ [3]. Tương tự, nghiên cứu của Hu và cộng sự (2012) tại Trung Quốc cũng cho thấy, rs2856718 của gen HLA-DQ chiếm ưu thế ở Dân tộc Hán, có tương quan mạnh với khả năng tự thải trừ HBV và có tác dụng bảo vệ chống lại sự tiến triển của $\mathrm{HCC}$, làm giảm đáng kể nguy cơ ung thư gan [7]. Trong nghiên cứu bởi Ji và cộng sự (2014) tại Trung Quốc, rs2856718 có tương quan với sự giảm nhiếm HBV, và alen $\mathrm{G}$ có tương quan với nguy cơ tiến triển xơ gan [6]. Như vậy, vai trò của đa hình đơn nucleotide rs2856718 của gen HLA-DQ đối với tiến triển ung thư gan ở các quần thể khác nhau là không đồng nhất. Điều này có thể do sự khác nhau về quần thể nghiên cứu, cách thiết kế nghiên cứu như cõ̃ mẫu, cách chọn đối tượng tham gia nghiên cứu để loại trừ yếu tố nhiễu, cách chia nhóm để phân tích mối tương quan.

\section{KẾT LUẬN}

Nghiên cứu đã xác định được tỉ lệ kiểu gen GG, AG và $A A$ ở nhóm bệnh nhân ung thư biểu mô tế bào gan là $39,8 \%, 46,2 \%$ và $14 \%$, ở nhóm chứng là $30,1 \%, 53,8 \%$ và $16,1 \%$. Tần số alen $A$ và $G$ của nhóm bệnh là 0,371 và 0,629, ở nhóm chứng là 0,43 và 0,57 . Chưa thây được mối liên quan giữa SNP rs2856718 gen HLA-DQ với ung thư biểu mô tế bào gan hay với một số yếu tố nguy cơ của ung thư biểu mô tế bào gan.

LỜI CAM ƠN. Nghiên cứu được thực hiện với sự hỗ trợ kinh phí của đề tài mã số 108.022019.307, thuộc Quỹ phát triển khoa học và công nghệ quốc gia (NAFOSTED). Nhóm nghiên cứu trân trọng cảm ơn Bệnh viện $K$ và Bệnh viện Đại học Y Hà Nội đã cung cấp mẫu nghiên cứu.

\section{TÀI LIÊU THAM KHẢO}

1. https://gco.iarc.fr/today/data/factsheets/populations.

2. Choo SY.(2007) The HLA system: genetics, immunology, clinical testing, and clinical implications. Yonsei medical journal 2007;48:11-23.

3. Al-Qahtani A, Al-Anazi $R$, Abdo A, et al. Association between HLA Variations and Chronic Hepatitis B Virus Infection in Saudi Arabian Patients. PLOS ONE. 2014;9(1), e80445.

4. Xu T, Zhu $A$, Sun $M$, et al. Quantitative assessment of HLA-DQ gene polymorphisms with the development of hepatitis B virus infection, clearance, liver cirrhosis, and hepatocellular carcinoma. Oncotarget. 2017;9(1):96-109.

5. Gao X., Liu W., Zhang $X_{\text {., }}$ et al. (2016). Genetic polymorphism of HLA-DQ confers susceptibility to hepatitis B virus-related hepatocellular carcinoma: a case-control study in Han population in China. Tumor Biol, 37(9), 12103-12111.

6. Ji X., Zhang Q., Li B., et al. (2014). Impacts of human leukocyte antigen DQ genetic polymorphisms and their interactions with hepatitis $B$ virus mutations on the risks of viral persistence, liver cirrhosis, and hepatocellular carcinoma. Infect Genet Evol, 28, 201-209.

7. Hu L., Zhai X., Liu J., et al. (2012). Genetic variants in human leukocyte antigen/DP-DQ influence both hepatitis $B$ virus clearance and hepatocellular carcinoma development. Hepatology, 55(5), 1426-1431.

8. https://www.ncbi.nlm.nih.gov/snp/rs2856718?hori zontal_tab=true\#frequency_tab.

9. Mbarek H, Ochi H, Urabe $Y$, et al. A genomewide association study of chronic hepatitis $B$ identified novel risk locus in a Japanese population. Hum Mol Genet. 2011;20(19): 3884-3892. 